\title{
PRIMER REGISTRO DE SYNEMOSYNA PETRUNKEVITCHI (CHAPIN, 1922) (ARANEAE: SALTICIDAE) EN CUBA
}

\author{
Franklyn Cala-Riquelme
}

\begin{abstract}
Departamento de Zoología, Centro Oriental de Ecosistemas y Biodiversidad (BIOECO). Museo de Historia Natural “Tomas Romay”, José Antonio Saco No 601, esq Barnada, Santiago de Cuba, Cuba. CP: 90100. franklyn@bioeco.ciges.inf.cu
\end{abstract}

\section{RESUMEN}

Se registra la presencia de la araña mimética Synemosyna petrunkevitchi para Cuba, comentándose además aspectos sobre su ecología.

Palabras clave: Synemosyna, mimética-hormiga, distribución, ecología, Cuba.

\section{ABSTRACT}

The mimetic ant-like Synemosyna petrunkevitchi is recorded from Cuba with comments about ecological aspect.

Key works: Synemosyna, ant-like, distribution, ecology, Cuba.

El género Synemosyna Hentz, 1846 resulta un carismático grupo de arañas caracterizadas por su marcada similitud a los géneros de hormigas Pseudomyrmex, Dolichoderine y Crematogaster, y de distribución restringida al Continente Americano (Galiano, 1966; Platnick, 2008). En el Caribe, este género se encuentra representado solo por la especie S. smithi Peckham et Peckham 1893, localizada en el archipiélago cubano y en la isla de St. Vicente de las Antillas Menores (Bryant, 1940; Platnick, 2008).
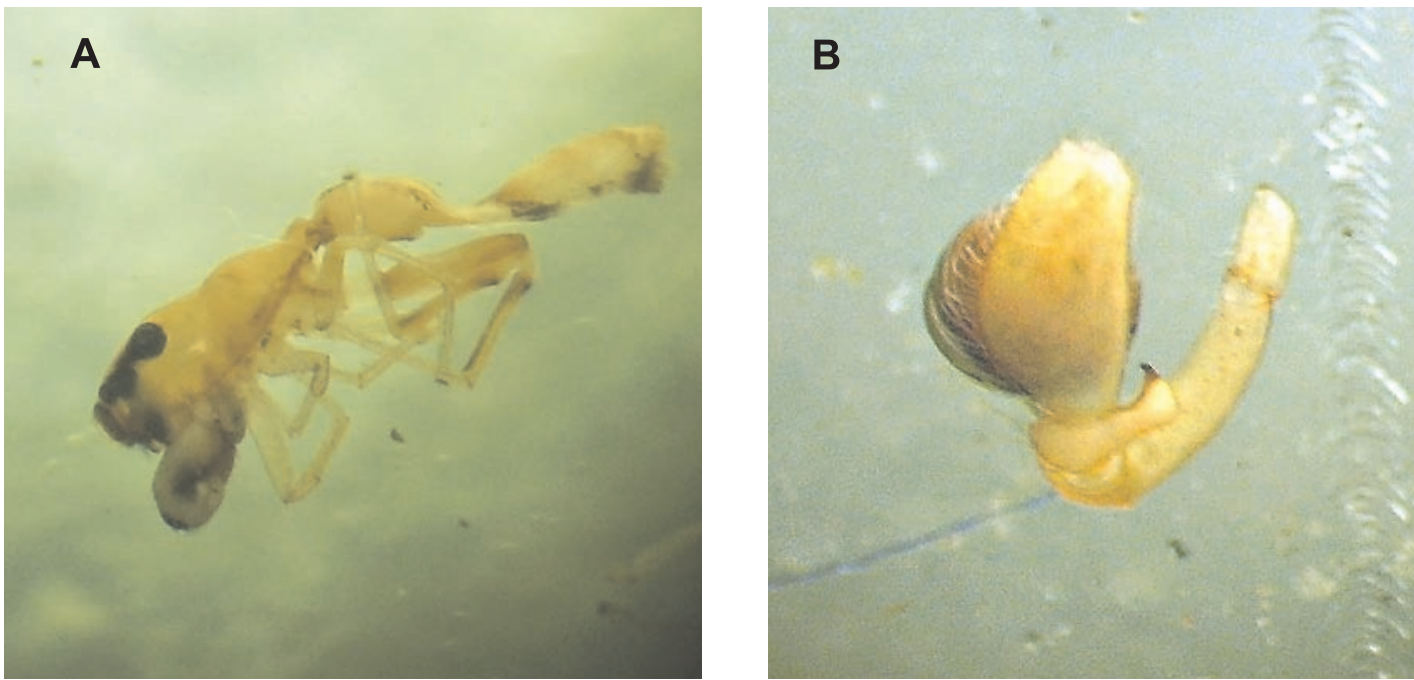

Figura 1. A. Macho adulto de Synemosyna petrunkevitchi. B. Genitalia de macho adulto. 
Recientemente, durante un estudio de campo realizado en la Reserva Ecológica Siboney-Juticí, provincia Santiago de Cuba, se detectó la presencia de dos machos adultos y un macho inmaduro de la especie S. petrunkevitchi (Chapin, 1922) (fig.1). Este hallazgo representa el primero de su tipo de la especie en el Caribe. Los individuos fueron colectados en agosto del 2008, en ramas laterales de Gymnanthes lucida (Euphorbiaceae) del matorral xeromorfo subcostero, entre 1.10 y 2.00 metros del suelo y a unos $90 \mathrm{msnm}$. S. petrunkevitchik es una especie conocida únicamente de Norteamérica (Edward y Hill, 2008).

En Cuba, la especie fue detectada asociada a colonias de la hormiga Pseudomyrmex pallidus (Smith), las cuales fueron localizadas en el área de uso público de la Reserva Ecológica. El fenómeno de imitación (mimetismo) resulta bastante frecuente dentro del orden Araneae y un rasgo distintivo dentro del género Synemosyna, el cual presenta una forma más especializada de la mímica conocida como "mímica Wasmannian" caracterizada por la convivencia del imitador con la forma imitada, en este caso la hormiga Pseudomyrmex (Wasmann, 1894).

Material estudiado.Dos (2) machos adultos, 1 macho inmaduro. Reserva Ecológica Siboney-Jutici, 14-16 de agosto 2008. Cala-Riquelme.

\section{AGRADECIMIENTOS}

Muchas gracias a Alexander Sánchez-Ruiz (BIOECO) por su valiosa ayuda en la revisión del artículo y las sugerencias.

\section{LITERATURA CITADA}

Bryant, E. B. 1940 Cuban spiders in the Museum of Comparative Zoology. Bull. Mus. comp. Zool. Harv. 86:247-554.

Edwards, G. B. y D. E. Hill. 2008. Representatives of the North American salticid fauna, revisited. Peckhamia 30.2, 29.

Galiano, M. E. 1966a. Salticidae (Araneae) formiciformes. V. Revisión del género Synemosyna Hentz. Rev. Mus. Argent. Cienc. Nat. Entomol. 1 (6): 370-371, f.15, 17, 40-41.

Galiano M. E. 1966b. Salticidae (Araneae) formiciformes. V. Revision del genero Synemosyna Hentz. Rev. Mus. Argent. Cienc. Nat. Entomol. 1 (6): 348-353, f8-11, 44-46, 49, 61.

Platnick, N. I. 2008. The World Spider Catalog, version 4.5. American Museum of Natural History, New York. Online at http://research.amnh.org/entomology/spiders/ catalog/index.html.

Wasmann, E. 1894. Kritisches Verzeichniss der myrmecophilin und termitophilen Arthropoden. Felix Dames, Berlin xi +231 pp. 